\title{
Rate Study of Fast Intermacromolecular Reactions by Laser-Pulse-Induced Phosphorescence Quenching
}

\author{
Kazuyuki Horie and Itaru Mita \\ Institute of Space and Aeronautical Science, University of Tokyo, \\ Komaba, Meguro-ku, Tokyo 153, Japan.
}

(Received December 7, 1976)

\begin{abstract}
As the study of the mechanism of diffusion-controlled polymerpolymer reactions, the rate constants $k_{\mathrm{q}}$ for phosphorescence quenching of benzil moiety by anthracene moiety each attached to the chain end of different monodisperse polystyrene have been measured in benzene at $20-40^{\circ} \mathrm{C}$ by using 10 -nsec dye laser pulses. Quenching reactions of benzil phosphorescence by polystyrylanthracene (polymer-small molecule reactions) have also been observed. The $k_{\mathrm{q}}$ for polymer-small molecule reactions decreases to about one-half of $k_{\mathrm{q} 0}$, the rate constant for the reaction between benzil and 9-methylanthracene. The $k_{\mathrm{q}}$ for polymer-polymer reactions is approximately proportional to $P^{-0.32}$ in benzene for the range of $P=23-740$, where $P$ is the degree of polymerization of polystyrene moiety. Activation energies for $k_{\mathrm{q}}$ of both polymerpolymer and polymer-small molecule reactions correspond well to the temperature dependence of solvent viscosity.

KEY WORDS Rate Constant / Intermacromolecular Reaction / Diffusion Control / Phosphorescence / Quenching / Laser Pulse / Polystyrylbenzil / Polystyrylanthracene /
\end{abstract}

The chemical reactivity of a reactive group bonded to a macromolecule is often affected by physical properties of the macromolecule in the reaction medium. The reaction between reactivity and physical properties of macromolecules in solution has become of increasing interest in recent years. ${ }^{1}$ Fast reaction between two polymer radicals in the termination step of free-radical polymerization is a typical example of diffusion-controlled intermacromolecular reaction, ${ }^{2}$ which has been investigated by many authors. However, the polydispersity of the reacting polymer radicals and the complexity of the process for calculating $k_{\mathrm{t}}$ from kinetic data of polymerization make unreliable the data concerning the dependence of $k_{\mathrm{t}}$ on molecular weight, temperture, and solvent, and this situation has prevented the quantitative discussion of the diffusion-controlled process.

The dependence of rates of diffusion-controlled intermacromolecular reactions on various factors has been shown by Schnabel, et al., , ${ }^{3,4}$ with the pulse radiolysis method and by Shaulov, et al., ${ }^{5}$ with the ESR exchange broadening technique.
But the former method was applied only to the reaction of radicals randomly located along polymer chains in water. The latter technique is restricted to polymers with fairly small molecular weights.

Triplet-triplet energy transfer in the cases where the lowest triplet energy of donor is higher than that of acceptor by more than $20 \mathrm{~kJ} \mathrm{~mol}^{-1}$ is known to be a diffusion-controlled process. ${ }^{6}$ Thus, the triplet-triplet energy transfer between donor and acceptor each attached to different polymer chain is supposed to be a suitable model for intermacromolecular diffusion-controlled reactions. The rate of energy transfer can be measured by the observation of triplet-triplet absorption, phosphorescence, or delayed fluorescence. As already discussed in a previous communication, ${ }^{7}$ triplet quenching of rather long lifetime fits in time scale of the measurements of intermacromolecular reactions, while fluorescence quenching is too fast to be applied to them. The quenching rate of benzil phosphorescence by anthracence, which we have measured in benzene solution of polystyrene at room tem- 
perature, ${ }^{7}$ suggests that this system is convenient also for the study of the diffusion-controlled intra- and inter-macromolecular reactions.

In a present paper, we report first the syntheses of polystyrene having a benzil or anthracene group at the chain end (abbreviated as PS-B or PS-A), and then the rate constants for the quenching of benzil phosphorescence by PS-A (polymer-small molecule reaction) and those for the phosphorescence quenching of PS-
B by PS-A (polymer-polymer reaction) will be presented as the results of measurements in benzene at $20-40^{\circ} \mathrm{C}$ by using $10-\mathrm{nsec}$ dye laser pulses.

\section{PREPARATION OF PS-B AND PS-A}

Benzil was bonded to the chain end of substantially monodisperse polystyrene by an ester linkage. The main synthetic route employed is illustrated by the following scheme:

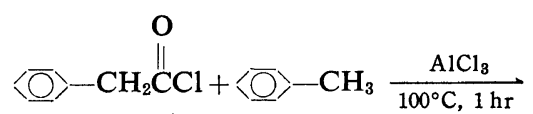

(I)<smiles>Cc1ccc(C(=O)Cc2ccccc2)cc1</smiles>

(II)<smiles>Cc1ccc(C(=O)c2ccccc2)cc1</smiles>

(III)

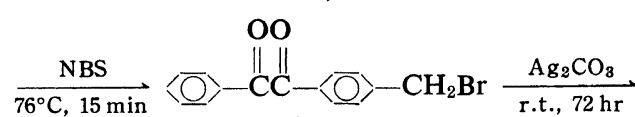

(IV)<smiles>O=C(c1ccccc1)c1ccc(CO)cc1</smiles>

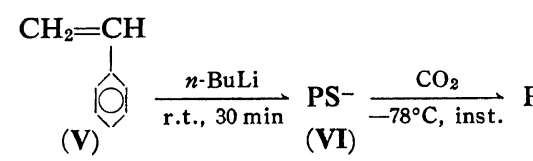<smiles>O=C(O)C(=O)S(=O)(=O)Cl</smiles>

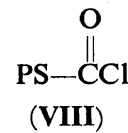

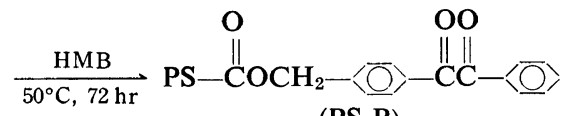

(PS-B)
Friedel-Crafts reaction of phenylacetyl chloride (I) in toluene gives 4-methyldeoxybenzoin (II), ${ }^{8}$ which is oxidized to 4 -methylbenzil (III). ${ }^{9}$ The 4-bromomethylbenzil $(\text { IV })^{10}$ prepared from the methylderivative (III) is converted to 4hydroxymethylbenzil (HMB), pale yellow needles of $\mathrm{mp} 58-61^{\circ} \mathrm{C}$, in order to introduce a nucleophilic group at the 4-position of benzil.

Living anionic polymerization of styrene $(\mathbf{V})$ in benzene with $n$-butyllithium and a trace of tetrahydrofuran gives substantially monodisperse polystyryl living anion (VI), ${ }^{11}$ whose chain end is changed to acid chloride (VIII) via carboxylic acid (VII). Strict removal of hydrogen chloride during the chlorination and of residual thionyl chloride from polystyrylcarbonyl chloride (VIII) after the reaction is required for preparing a phosphorescing polystyrene. Esterification of the acid chloride (VIII) with HMB in a sealed vessel gives polystyrylcarbonyloxymethylbenzil (PS-B). Visible absorption spectra of PS-B showed that the phosphorophore was bound to about $80 \%$ of the chain end of polystyrene.
Anthracene is attached to the chain end of substantially monodisperse polystyrene by the direct attack of living polystyryl anion (VI) to 9-chloromethylanthracene (XI), which is prepared from 9-anthraldehyde (IX) via 9-hydroxymethylanthracene $(\mathbf{X}){ }^{12}$ The yield of polystyrylanthracene (PS-A) was quantitative. The synthetic scheme is shown as follows:

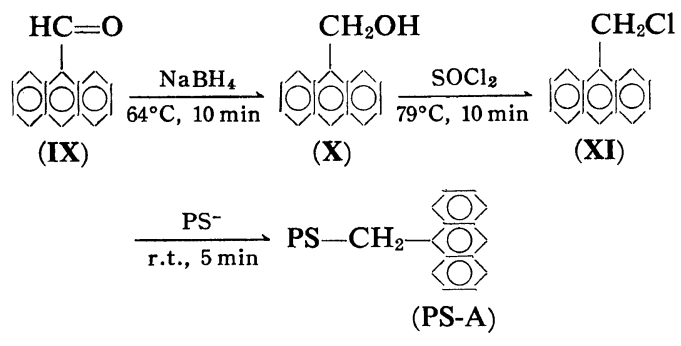

Molecular weights and molecular weight distributions of PS-B and PS-A measured with a gel permeation chromatograph (GPC) and a vapor-pressure osmometer (VPO) are shown in Table I. Some differences in molecular weights 
Rate Study of Fast Intermacromolecular Reactions

Table I. Characterization of PS-B and PS-A

\begin{tabular}{lcccc}
\hline Polymer & $\begin{array}{c}\bar{M}_{n} \text { by } \\
\text { GCP }\end{array}$ & $\begin{array}{c}\bar{M}_{n} \text { by } \\
\text { VPO }\end{array}$ & $\bar{M}_{w} / \bar{M}_{n}$ & $\begin{array}{c}\text { Degree of } \\
\text { polymeriza- } \\
\text { tion in } \\
\text { polystyrene } \\
\text { moiety }\end{array}$ \\
\hline PS23-B & $2.5 \times 10^{3}$ & $2.5 \times 10^{3}$ & 1.02 & 23 \\
PS25-A & $2.8 \times 10^{3}$ & $2.5 \times 10^{3}$ & 1.03 & 25 \\
PS60-B & $6.4 \times 10^{3}$ & $7.2 \times 10^{3}$ & 1.10 & 60 \\
PS71-A & $7.5 \times 10^{3}$ & $7.4 \times 10^{3}$ & 1.13 & 71 \\
PS660-B & $6.8 \times 10^{4}$ & - & 1.08 & 660 \\
PS740-A & $7.7 \times 10^{4}$ & $7.3 \times 10^{4 a}$ & 1.14 & 740 \\
\hline
\end{tabular}

a From viscosity measurement in toluene at $30^{\circ} \mathrm{C}$ with the relation ${ }^{24}[\eta]=1.10 \times 10^{-4} M^{0.725}$.

of PS-B and PS-A prepared from the same polystyryl anion (VI) may be caused by the procedure of their reprecipitations. Direct termination of the living anion (VI) with methanol gave polystyrene with $\bar{M}_{n}=6.4 \times 10^{3}$ in the case corresponding to PS60-B and PS71-A.

\section{TRIPLET LIFETIMES OF PHOSPHOROPHORES}

Triplet lifetimes $\tau$ and $\tau_{0}$ of benzil derivatives and PS-B in the presence and absence of quenchers, respectively, were calculated from the decay curves of phosphorescence intensity induced by laser pulses of $406 \mathrm{~nm}$ with a half width of $10 \mathrm{nsec}$. The schematic diagram of the apparatus is illustrated in Figure 1. Typical

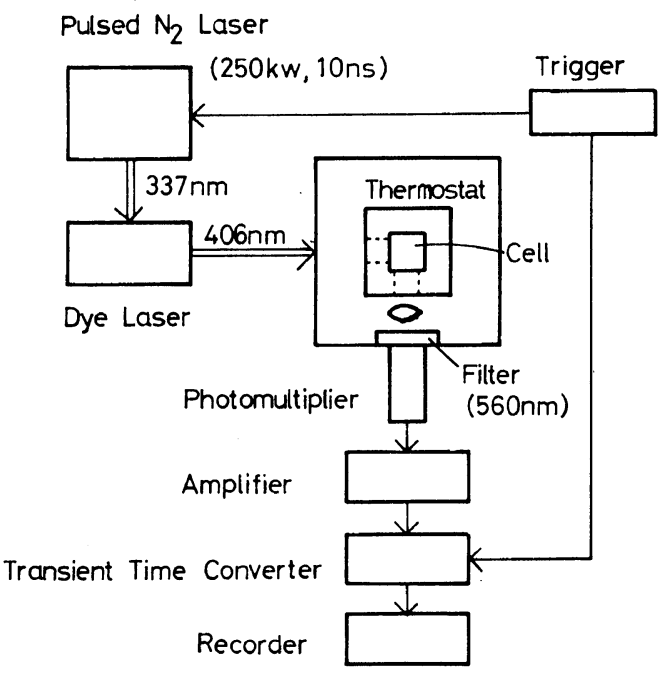

Figure 1. Schematic diagram of the apparatus.

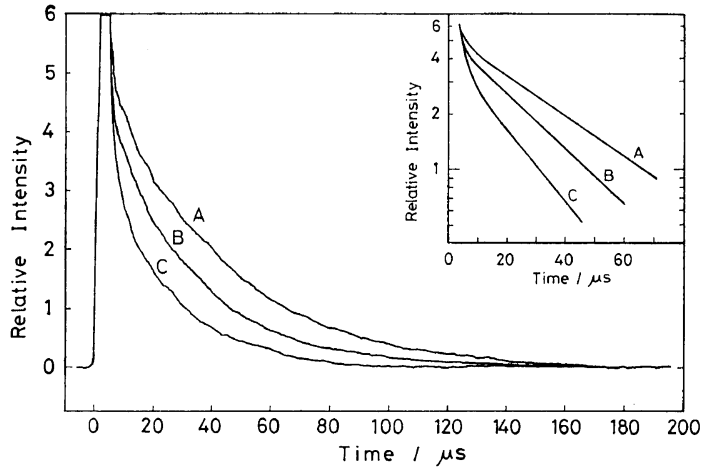

Figure 2. Phosphorescence decay curves of PS60-B in the absence (A) and presence (B, C) of PS71-A in benzene at $30^{\circ} \mathrm{C}$, and their semilogarithmic plots (Insert). Concentration of PS71-A: B, 1.04× $10^{-5} \mathrm{~mol} / \mathrm{dm}^{3} ; \mathrm{C}, 2.14 \times 10^{-5} \mathrm{~mol} / \mathrm{dm}^{3}$.

decay curves as well as their semilogarithmic plots are shown in Figure 2. The combination of colored glass and interference filters eliminates the fluorescence of benzil moiety at $505 \mathrm{~nm}$. The linear relationship of the logarithmic intensity of phosphorescence at $560 \mathrm{~nm}$ against time is attained within several $\mu \mathrm{sec}$ after the excitation. Slopes of straight lines in Figure 2 (Insert) give $\tau^{-1}$ or $\tau_{0}^{-1}$, depending on the presence or absence of quencher. The initial nonlinear decay in Figure 2 (Insert) is caused by the response characteristics of the amplifier used.

Triplet lifetimes $\tau_{0}$ of benzil derivatives and PS-B in benzene at $25^{\circ} \mathrm{C}$ are listed in Table II, together with apparent activation energies $\mathrm{E}$ for $\tau_{0}^{-1}$ in the temperature range of $20-40^{\circ} \mathrm{C}$. No shifts of fluorescence and phosphorescence peaks were observed in the luminescence spectra of these benzil derivatives, by comparison with those of benzil.

Table II. Triplet lifetimes $\tau_{0}$ in benzene at $25^{\circ} \mathrm{C}$ and their temperature dependences $E$

\begin{tabular}{lcc}
\hline \multicolumn{1}{c}{ Phosphorophore } & $\tau_{0}, \mu \mathrm{sec}$ & $E, \mathrm{~kJ} / \mathrm{mol}$ \\
\hline Benzil & 54 & 30.5 \\
4-Methylbenzil & 47 & - \\
4-Bromomethylbenzil & 17 & - \\
4-Hydroxymethylbenzil & 30 & - \\
PS23-B & 40 & 28.2 \\
PS60-B & 50 & 31.0 \\
PS660-B & 29 & 21.5 \\
\hline
\end{tabular}


The value of $\tau_{0}=57 \mu \mathrm{sec}$ for benzil is more reliable than the previous results, ${ }^{7}$ since a much shorter pulse half-width and a larger total intensity of the excitation flash have facilitated the analysis of the decay curves in the present work. The internal heavy-atom effect reduces $\tau_{0}$ for 4-bromomethylbenzil to one-third of $\tau_{0}$ for benzil, and the hydroxyl group in 4-hydroxymethylbenzil also diminishes its $\tau_{0}$ value.

It is of interest that $\tau_{0}$ for PS60-B is almost as large as $\tau_{0}$ for benzil, though benzil itself could not be regarded as a sufficient lowermolecular-weight model of PS-B. This result suggests that the residual long chain of polystyrene in PS-B has little effect on the phosphorescence rate $k_{\mathrm{p}}$ and the radiationless deactivation rate $k_{\mathrm{d}}$ of benzil moiety, where $k_{\mathrm{p}}$ and $k_{\mathrm{d}}$ are related to $\tau_{0}$ by

$$
\tau_{0}=1 /\left(k_{\mathrm{p}}+k_{\mathrm{d}}\right)
$$

It has been reported ${ }^{13}$ that $k_{\mathrm{d}}$ increases rapidly with increasing chain length of aliphatic $\alpha$ diketones because of the increased number of modes of vibrational deactivation for the dissipation of absorbed energy. It would be suggested in the present case that the stiff aromatic moiety between $\alpha$-diketone and the polystyrene chain in PS-B prevents harmonic vibrations for the energy dissipation. A smaller $\tau_{0}$ for the initial precipitate of PS60-B approached to the value of $\tau_{0}$ determined for benzil after repeated precipitations. The repeated precipitations also increased $\tau_{0}$ for PS23-B and PS660-B to the values shown in Table II, but they are still smaller than $\tau_{0}$ for benzil. This is probably due to impurities which became attached to the polymer chains during the last two steps of the preparation of PS-B.

The effects of temperature on triplet lifetimes in fluid solution are not yet fully understood. If the phosphorescence rate $k_{\mathrm{p}}$ is not or only slightly temperature dependent, ${ }^{14}$ the large temperature dependences of $\tau_{0}$ for benzil and PS-B shown in Table II should be caused by the increase in $k_{\mathrm{d}}$ with increasing temperature. A viscosity effect has been suggested ${ }^{15}$ for the rapid increase in $k_{\mathrm{d}}$, but the temperature dependence of solvent viscosity in the same temperature range $\left(10.6 \mathrm{~kJ} \mathrm{~mol}^{-1}\right)$ is not sufficient to explain the present results. Some modes of vibration with higher activation energies in benzil moiety, besides impurity quenching, might be responsible for the deactivation processes of its triplet state in solution.

\section{RATES OF POLYMER - SMALL MOLECULE REACTIONS}

The bimolecular rate constant of phosphores-

Table III. Experimental conditions and results at $30^{\circ} \mathrm{C}$ in benzene

\begin{tabular}{|c|c|c|c|c|c|c|}
\hline $\begin{array}{l}\text { Phospho- } \\
\text { rophore }\end{array}$ & $\begin{array}{l}{[\mathrm{P}] \times 10^{3}} \\
\mathrm{~mol} / \mathrm{dm}^{3}\end{array}$ & Quencher & $\begin{array}{l}{[\mathrm{Q}] \times 10^{5}} \\
\mathrm{~mol} / \mathrm{dm}^{3}\end{array}$ & $\begin{array}{c}\text { Polymer } \\
\text { concentration, } \\
\mathrm{g} / \mathrm{dm}^{3}\end{array}$ & $\begin{array}{c}(1 / \tau) \times 10^{-4} \\
\sec ^{-1}\end{array}$ & $\begin{array}{c}k_{\mathrm{q}} \times 10^{-9} \\
\mathrm{dm}^{3} \mathrm{~mol}^{-1} \mathrm{sec}^{-1}\end{array}$ \\
\hline Benzil & 5.0 & - & - & - & 2.26 & - \\
\hline Benzil & 5.0 & Anthracene & 0.53 & 一 & 5.65 & 6.42 \\
\hline Benzil & 5.0 & Anthracene & 1.06 & - & 9.25 & 6.59 \\
\hline Benzil & 5.0 & 9-Methylanthracene & 1.02 & 一 & 6.32 & 3.98 \\
\hline Benzil & 5.0 & PS25-A & 0.87 & 0.02 & 3.84 & 1.82 \\
\hline Benzil & 5.0 & PS71-A & 1.08 & 0.08 & 4.01 & 1.62 \\
\hline Benzil & 5.0 & PS740-A & 0.99 & 0.8 & 3.76 & 1.52 \\
\hline PS23-B & 1.0 & 一 & - & 3.1 & 3.06 & - \\
\hline PS23-B & 1.0 & PS25-A & 0.77 & 3.1 & 3.93 & 1.13 \\
\hline PS23-B & 1.0 & PS25-A & 1.54 & 3.2 & 5.01 & 1.26 \\
\hline PS60-B & 1.0 & - & - & 8.0 & 2.51 & 一 \\
\hline PS60-B & 1.0 & PS71-A & 1.04 & 8.1 & 3.43 & 0.886 \\
\hline PS60-B & 1.0 & PS71-A & 2.14 & 8.2 & 4.44 & 0.901 \\
\hline PS660-B & 0.33 & - & - & 28 & 3.76 & - \\
\hline PS660-B & 0.34 & PS740-A & 3.11 & 31 & 5.29 & 0.492 \\
\hline PS660-B & 0.41 & PS740-A & 6.06 & 38 & 6.56 & 0.463 \\
\hline
\end{tabular}


Rate Study of Fast Intermacromolecular Reactions

Table IV. Quenching rate constants $k_{\mathrm{q}}$ for polymer-small molecule reactions in benzene and their activation energies $E_{\mathrm{q}}$

\begin{tabular}{|c|c|c|c|c|c|c|}
\hline \multirow{2}{*}{ Phosphorophore } & \multirow{2}{*}{ Quencher } & \multicolumn{3}{|c|}{$k_{\mathrm{q}} \times 10^{-9}, \mathrm{dm}^{3} \mathrm{~mol}^{-1} \mathrm{sec}^{-1}$} & \multirow{2}{*}{$E_{\mathrm{q}}, \mathrm{kJ} / \mathrm{mol}$} & \multirow{2}{*}{$k_{\mathrm{q}} / k_{\mathrm{q} 0}$ at $30^{\circ} \mathrm{C}$} \\
\hline & & $20^{\circ} \mathrm{C}$ & $30^{\circ} \mathrm{C}$ & $40^{\circ} \mathrm{C}$ & & \\
\hline Benzil & Anthracene & 5.9 & 6.5 & 7.7 & 10.2 & - \\
\hline Benzil & 9-Methylanthracene & 3.7 & 4.0 & 4.8 & 9.9 & 1.0 \\
\hline Benzil & PS25-A & 1.6 & 1.8 & 2.2 & 12.0 & 0.46 \\
\hline Benzil & PS71-A & 1.4 & 1.6 & 1.8 & 9.4 & 0.41 \\
\hline Benzil & PS740-A & 1.3 & 1.5 & 1.8 & 10.3 & 0.38 \\
\hline
\end{tabular}

cence quenching $k_{\mathrm{q}}$ can be calculated by using

$$
1 / \tau=1 / \tau_{0}+k_{\mathrm{q}}[\mathrm{Q}]
$$

where [Q] is the concentration of quencher. Experimental conditions as well as $1 / \tau$ and $k_{\mathrm{q}}$ values obtained are given in Table III for measurements at $30^{\circ} \mathrm{C}$, where $[\mathrm{P}]$ is the concentration of phosphorophore. The values of $k_{\mathrm{q}}$ for different [Q] in a certain phosphorophorequencher system are in good accord.

The quenching rate constants $k_{\mathrm{q}}$ of anthracene, 9-methylanthracene and PS-A for benzil phosphorescence are summarized in Table IV. These values represent the characteristics of the rate of encounter of a small molecule with a chain end group of a flexible macromolecule.

The quenching rate constant $k_{\mathrm{q}}$ is given by a modified Smoluchowski equation

$$
k_{\mathrm{q}}=4 \pi \gamma R\left(D_{\mathrm{P}}+D_{\mathrm{Q}}\right)
$$

where $R$ is the encounter radius between phosphorescing and quenching moieties, $D_{\mathrm{P}}$ and $D_{\mathrm{Q}}$ are their respective diffusion coefficients, and $\gamma$ is a steric factor. Equation 3 can be changed to eq 4 in the case of encounters between two spherical particles with the same size, by assuming the Einstein-Stokes relation between the solvent viscosity $\eta$ and the diffusion coefficient of the particles:

$$
k_{\mathrm{q}}=8 \gamma k_{\mathrm{B}} T / 3 \eta
$$

where $k_{\mathrm{B}}$ is Boltzmann's constant and $T$ is temperature. Steric factors $\gamma$ are calculated from eq 4 to be 0.54 for benzil-anthracene reaction and 0.33 for benzil-9-methylanthracene reaction. Qualitative discussion of the steric factors smaller than unity has been given previously. Decrease in $\gamma$ for the latter is due to the introduction of a methyl group at the 9-position of anthracene. So, $k_{\mathrm{q}}$ for benzil-9-methylanthracene reaction is adopted as the rate constant for the model reaction $k_{\mathrm{q} 0}$, i.e., the reaction between two small molecules.

The introduction of polystyrene moieties to the 9-position of anthracene diminishes $k_{\mathrm{q}}$ to be about one-half $k_{\mathrm{q} 0}$, then $k_{\mathrm{q}}$ approaches a constant value with increașing molecular weight of polystyrene moieties. Activation energies $E_{\mathrm{q}}$ for the quenching reactions in Table IV are substantially the same, considering the experimental accuracy, and agree with the temperature dependence of the solvent viscosity $(10.6 \mathrm{~kJ}$ $\left.\mathrm{mol}^{-1}\right)$. This agreement suggests the applicability of eq 3 to polymer-small molecule reactions, since small molecules can penetrate almost freely through polymer coils in the present range of polymer concentration. ${ }^{7} \quad D_{\mathrm{Q}}$ in eq 3 may be neglected in comparison with $D_{\mathrm{P}}$, and the value of 0.5 for $k_{\mathrm{q}} / k_{\mathrm{q} 0}$ is expected for encounter-controlled polymer-small molecule reactions. The slight deviation of $k_{\mathrm{q}} / k_{\mathrm{q} 0}$ values in Table IV from 0.5 might be minimized by a more appropriate selection of a model compound as a low-molecular-weight analog PS-A. For a more detailed discussion it must be clarified whether the value of $D_{\mathrm{Q}}$ is comparable to that of the translational diffusion coefficient for the center of gravity of the polymer, $D_{\mathrm{G}}$, since the dependence of the mean-square displacement of a certain moiety in a polymer chain differs for time scales shorter and larger than relaxation time of the polymer coil. ${ }^{16}$ However, it is assumed here that the segmental diffusion coefficient of the chain end moiety of PS-A $D_{Q}$ is, as $D_{G}$, much smaller than that of free benzil.

Encounter-controlled reactions of small quenchers with fluorescing ${ }^{17,18}$ or triplet ${ }^{19}$ group attached along the polymer chain have been 
reported recently. Decreases in $k_{\mathrm{q}}$ by factors between $1 / 2$ and $1 / 3$ compared with that for model reactions of corresponding monomer analogs are in good accord with the present results in spite of the variety of numbers and positions of luminophores in the polymer chains.

In conclusion, the rate constants $k_{\mathrm{q}}$ for encounter-controlled polymer-small molecule reactions can be well expressed by eq 3 , where $D_{\mathrm{Q}}$ represents the diffusion coefficient of the terminal segment including the reacting group, $R$ is the encounter radius of segment size, and $\gamma$ stands for the steric hindrance due to the part of polymer chain adjacent to the reacting moiety causing a less efficient approach of the small molecule. A careful selection of a model compound as a low-molecular-weight analog of the polymer reactant is required for the discussion of polymer effects for the rates of polymer-small molecule reactions.

\section{RATES OF POLYMER-POLYMER REACTIONS}

The rate constants $k_{\mathrm{q}}$ for quenching of PS-B by PS-A are summarized in Table V, and illustrated in Figure 3 against the degree of polymerization $P$ of the reactants. We think that they are the first results of encounter-controlled rate constants measured directly for intermacromolecular reactions between two chain ends of substantially monodisperse macromolecules.

The rate constant $k_{\mathrm{q}}$ decreases with increasing molecular weights of the reactants. Their activation energies $E_{\mathrm{q}}$ are independent of the molecular weights of PS-B and PS-A, and have almost equal value to the temperature dependence of the solvent viscosity. Though this fact is evidence for the diffusion-controlled mechanism of the present reactions, it gives no de-

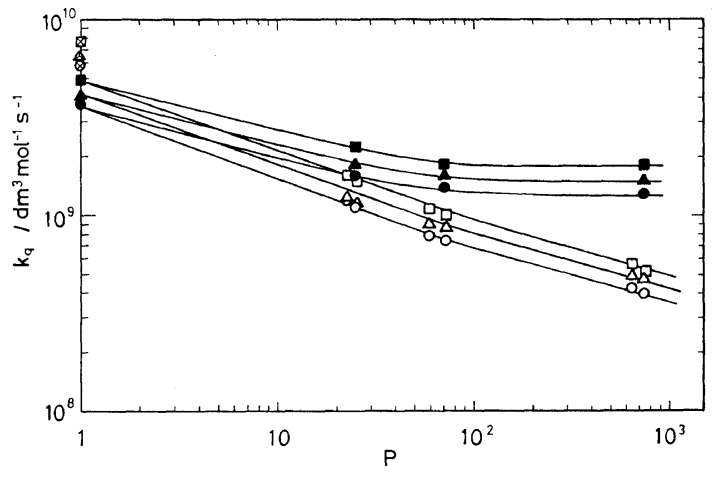

Figure 3. Dependences of $k_{q}$ for polymer-polymer reactions $(O, \triangle, \square)$ and for polymer-small molecule reactions $(\boldsymbol{O}, \boldsymbol{\Delta}, \boldsymbol{\square})$ on degree of polymerization $P$ of PS-B and PS-A (plots for $P=1$ correspond to 9-methylanthracene as quencher), and $k_{\mathrm{q}}$ for benzil-anthracene reaction $(\otimes, \Delta, \otimes)$ : Temperature, $\bigcirc, \odot, \otimes, 20^{\circ} \mathrm{C} ; \triangle, \Delta, \Delta, 30^{\circ} \mathrm{C}$; $\square, \square, \otimes, 40^{\circ} \mathrm{C}$.

tailed information about the mechanism, since both the rate of conformation change of segments and the translational diffusion coefficient for the center of gravity of the polymer are inversely proportional to solvent viscosity.

The slopes in Figure 3 show that $k_{\mathrm{q}}$ is approximately proportional to $P^{-0.32}$ in benzene for the range of $P=23-740$. This value of exponent may be compared with that for the recombination of polyoxyethylene radicals randomly generated along polymer chains $(-0.39$ for the same range of $P$ ). ${ }^{3}$ The exponent for the molecular weight dependence of $D_{G}$ of polystyrene in benzene is supposed to be -0.59 , by using Mark-Houwink-Sakurada parameter $a=0.78$ for this system $^{20}$ and the relation $D_{\mathrm{G}} \sim$ $M^{-\beta}$, where $\beta=(1+a) / 3$. This value differs markedly from the present experimental result, which does not support the idea ${ }^{5}$ that the

Table V. Quenching rate constants $k_{\mathrm{q}}$ for polymer-polymer reactions in benzene and their activation energies $E_{\mathrm{q}}$

\begin{tabular}{ccccccc}
\hline \multirow{2}{*}{ Phosphorophore } & \multirow{2}{*}{ Quencher } & \multicolumn{2}{c}{$k_{\mathrm{q} \times 10^{-9}, \mathrm{dm}^{3} \mathrm{~mol}^{-1} \mathrm{sec}^{-1}}$} & \multirow{2}{*}{$E_{\mathrm{q}}, \mathrm{kJ} / \mathrm{mol}$} & \multirow{2}{*}{$k_{\mathrm{q}} / k_{\mathrm{q} 0}$ at $30^{\circ} \mathrm{C}$} \\
\cline { 2 - 6 } & & $20^{\circ} \mathrm{C}$ & $30^{\circ} \mathrm{C}$ & $40^{\circ} \mathrm{C}$ & & \\
\hline Benzil & 9-Methylanthracene & 3.7 & 4.0 & 4.8 & 9.9 & 1.0 \\
PS23-B & PS25-A & 1.2 & 1.2 & 1.6 & 12.1 & 0.30 \\
PS60-B & PS71-A & 0.76 & 0.89 & 1.04 & 11.8 & 0.22 \\
PS660-B & PS740-A & 0.41 & 0.48 & 0.53 & 9.5 & 0.12 \\
\hline
\end{tabular}


mechanism of polymer-polymer reactions can be explained by eq 3 together with the use of $D_{\mathrm{Q}}$ of reactants instead of $D_{\mathrm{P}}$ and $D_{\mathrm{Q}}$.

The observed values of $k_{\mathrm{q}}$ in the present paper agree in the order of magnitude with those obtained by triplet-triplet absorption measurements ${ }^{21}$ for quenching reactions between triplet and quenching groups randomly incorporated in poly(methyl methacrylate)s respectively, but are fairly large in comparison with the usual rate constants for termination $k_{\mathrm{t}}$ in radical polymerization of styrene. ${ }^{22}$ The difference would be caused by a larger encounter radius for triplet-triplet energy transfer and a smaller steric hindrance for the encounter, compared with the case of radical recombination. Nevertheless, phosphorescence quenching may be regarded as a convenient model of diffusioncontrolled intermacromolecular reactions, since the effects of polymer chains on the reactivity should be similar to those for fast radical termination reactions.

Quantitative discussion about the mechanism of encounter-controlled intermacromolecular reactions will be given in the near future with further experimental results for polymers with higher molecular weights and in different solvents.

\section{EXPERIMENTAL}

\section{Samples}

Preparations of 4-methyldeoxybenzoin (II), ${ }^{8}$ 4-methylbenzil (III), ${ }^{9}$ and 4-bromomethylbenzil $(\mathbf{I V})^{10}$ were carried out as described in the literature. The recrystallized products were identified by melting points and IR and NMR spectra.

The 4-hydroxymethylbenzil (HMB) was prepared by the reaction of 4-bromomethylbenzil $(2.68 \mathrm{~g})$ with silver carbonate $(2.71 \mathrm{~g})$ in acetone $\left(30 \mathrm{~cm}^{3}\right)$ and water $\left(3.0 \mathrm{~cm}^{3}\right)$ for $72 \mathrm{hr}$ at room temperature in a $100-\mathrm{cm}^{3}$ flask with magnetic stirrer and reflux condenser. Then the mixture was refluxed for $30 \mathrm{~min}$ and filtered. The evaporation of solvents from the yellow filtrate gave a crude yellow solid $(2.24 \mathrm{~g})$, whose recrystallization from 10-\% carbon tetrachloride solution resulted in pale yellow needles $(0.75 \mathrm{~g})$, $\mathrm{mp} 58-61^{\circ} \mathrm{C}$. NMR chemical shifts in $\mathrm{CDCl}_{3}$ : $2.08,4.76,7.48,7.90 \mathrm{ppm}$ from TMS with intensity ratio $1: 2: 5: 4$. IR spectrum: 1665 ,
$3250 \mathrm{~cm}^{-1}$.

Anionic polymerizations of styrene $(\mathbf{V})$ in benzene were carried out with $n$-butyllithium as an initiator under high vacuum system. ${ }^{11}$ Purifications of monomer and solvent were performed in the usual manner for living polymerization. $n$-Butyllithium in hexane was supplied by $E$. Merck Japan. The red polystyryl living anion (VI) obtained was divided into several aliquots and stored in a refrigerator for further use.

Polystyrylcarboxylic acid (VII) was prepared by pouring the living anion solution $\left(26 \mathrm{~cm}^{3}\right)$ onto tetrahydrofuran $\left(40 \mathrm{~cm}^{3}\right)$ saturated with excess dry ice $(20 \mathrm{~g})$ under nitrogen atmosphere. The mixture of concentrated hydrochloric acid $\left(1 \mathrm{~cm}^{3}\right)$ and methanol $\left(5 \mathrm{~cm}^{3}\right)$ was added to the system. The polymer (VII) was isolated by precipitation in methanol $\left(800 \mathrm{~cm}^{3}\right)$, filtered, and dried.

The reaction of polystyrylcarboxylic acid $(0.69 \mathrm{~g})$ with distilled thionyl chloride $\left(1.0 \mathrm{~cm}^{3}\right)$ in benzene $\left(10 \mathrm{~cm}^{3}\right)$ for $72 \mathrm{hr}$ at room temperature in a $100-\mathrm{cm}^{3}$ flask with magnetic stirrer and outlet filled with calcium chloride gave a colorless solution of polystyrylcarbonyl chloride (VIII). Raising the temperature for this chlorination reaction ${ }^{23}$ resulted in a yellow solution, which did not lead to a phosphorescing polymer.

The colorless solution was placed in another flask connected by a break seal with an excess amount of degassed 4-hydroxymethylbenzil (45 $\mathrm{mg}$ in case of PS60-B). The residual thionyl chloride and hydrogen chloride in the solution was removed by the combination of repeated addition of tetrahydrofuran and benzene and their vacuum distrillation. After the addition of benzene $\left(8.0 \mathrm{~cm}^{3}\right)$, the flask was sealed off from the vacuum line. The reaction of the polymer acid chloride (VIII) with 4-hydroxymethylbenzil in benzene at $50^{\circ} \mathrm{C}$ for $72 \mathrm{hr}$ gave polystyrylcarbonyloxymethylbenzil (PS-B), which was repeatedly precipitated in methanol $\left(400 \mathrm{~cm}^{3}\right)$, filtered, and dried. The yield of pale yellow powder was $0.40 \mathrm{~g}$.

The 9-hydroxymethylanthracene $(\mathbf{X})$ and 9chloromethylanthracene (XI) were prepared according to the literature. ${ }^{12}$ The recrystallized products were identified by melting points and IR and NMR spectra.

Addition of polystyryl living anion in benzene 


\section{K. Horie and I. Mita}

$\left(26 \mathrm{~cm}^{3}\right)$ to 9 -chloromethylanthracene $(0.16 \mathrm{~g}$ in case of PS71-A) in tetrahydrofuran $\left(10 \mathrm{~cm}^{3}\right)$ prepared under high vacuum instantaneously gave a bright yellow solution of polystyrylanthracene (PS-A), which was repeatedly precipitated in methanol $\left(800 \mathrm{~cm}^{3}\right)$, filtered, and dried.

Benzil and anthracene were recrystallized from 5-\% ethanol and $2.5-\%$ benzene solutions, respectively. The GR-grade 9-methylanthracene and Dotite-Luminasol-grade benzene as a solvent for phosphorescence measurements were used as received.

\section{Characterization of $P S-B$ and $P S-A$}

Luminescence spectra of benzil derivatives and PS-B excited at $410 \mathrm{~nm}$ were measured with a Hitachi MPF-2A fluorescence spectrophotometer for solutions degassed and sealed under high vacuum. Absorption spectra of PS-B and PS-A were measured with a Shimadzu MPS-5000 spectrophotometer.

Number-average molecular weights $\bar{M}_{n}$ and molecular weight distributions of PS-B and PS-A were measured with a Toyo Soda HLC-801A gel permeation chromatograph at $40^{\circ} \mathrm{C}$ in tetrahydrofuran. The $\bar{M}_{n}$ was measured also with a Hewlett Packard 302 vapor pressure osmometer at $37^{\circ} \mathrm{C}$ in benzene.

Measurements of Phosphorescence Decay Curves

A schematic diagram of the apparatus is shown in Figure 1. The sample solution in a degassed and sealed rectangular quartz cell was set in a thermostat prepared in the workshop of our Institute, and irradiated by a pulse of 406-nm light from a dye laser (SSS DL-600) with 4,4'-diphenylstilbene, which was pumped by a $250-\mathrm{kW}$ pulsed nitrogen laser (Avco C950B) with a pulse half width of $10 \mathrm{nsec}$. Light emitted by the sample solution at the right angle was directed to a photomultiplier (Hamamatsu R374) through a combination of colored glass and interference filters (Toshiba VO53, VO54, KL56). The signal of the photomultiplier was amplified and fed into a transient time converter (Riken Denshi TCE-1000S) which permitted recording of the decay curve on a usual X-T-type pen recorder.

Acknowledgments. The authors express their gratitude to Assoc. Prof. K. Sanui of Sophia University for his kind discussion on the syntheses of PS-B, and to Drs. M. Yoshida and
H. Sakuragi of Tokyo University for the use of the fluorescence spectrophotometer.

\section{REFERENCES}

1. H. Morawetz, "Macromolecules in Solution," Second Ed., Wiley-Interscience, New York, N.Y., 1975, Chapter IX.

2. K. Horie, I. Mita, and H. Kambe, Polym. J., 4, 341 (1973).

3. U. Borgwardt, W. Schnabel, and A. Henglein, Makromol. Chem., 127, 176 (1969).

4. W. Görlich and W. Schnabel, ibid., 164, 225 (1973).

5. A. Yu. Shaulov, A. B. Shapiro, A. G. Sklyarova, A. M. Wasserman, A. L. Buchachenko, and E. G. Rozantsev, Eur. Polym. J., 10, 1077 (1974).

6. J. B. Birk, "Photophysics of Aromatic Molecules," Wiley-Interscience, New York, N.Y., 1970, p 537.

7. K. Horie and I. Mita, Polym. J., 8, 227 (1976).

8. P. M. G. Bavin, Can. J. Chem., 38, 911 (1960).

9. E. J. Corey and J. P. Schaefer, J. Am. Chem. Soc., 82, 918 (1960).

10. B. Krieg and G. Manecke, Chem. Ber., 101, 1480 (1968).

11. T. Altares, Jr., D. P. Wyman, and V. R. Allen, J. Polym. Sci., Part A, 2, 4533 (1964).

12. F. H. C. Stewart, Aust. J. Chem., 13, 478 (1960).

13. H. H. Richtol and F. H. Klappmeier, J. Chem. Phys., 44, 1519 (1966).

14. J. Langelaar, R. P. H. Rettschnick, and G. J. Hoijtink, ibid., 54, 1 (1971).

15. S. J. Ladner and R. S. Becker, ibid., 43, 3344 (1965).

16. M. Doi, Polym. J., 5, 288 (1973).

17. J. P. Bentz, J. P. Beyl, G. Beinert, and G. Weill, Eur. Polym. J., 11, 711 (1975).

18. B. Valeur and L. Monnerie, J. Polym. Sci., Polym. Phys. Ed., 14, 29 (1976).

19. G. Beck, G. Dobrowolski, J. Kiwi, and W. Schnabel, Macromolecules, 8, 9 (1975).

20. M. Cantow, G. Meyerhoff, and G. V. Schulz, Makromol. Chem., 49, 1 (1961).

21. J. Kiwi and W. Schnabel, Macromolecules, 9, 468 (1976).

22. C. H. Bamford, W. G. Barb, A. D. Jenkins, and P. F. Onyon, "The Kinetics of Vinyl Polymerization by Radical Mechanism," Butterworths, London, 1958, p 71.

23. H. Inagaki and T. Miyamoto, Makromol. Chem., 87, 166 (1965).

24. F. Danusso and G. Moraglio, J. Polym. Sci., 24, 161 (1957). 